\section{Ion exchange investigation for recovery of uranium from acidic pregnant leach solutions}

\begin{abstract}
The article describes studies on the separation of uranium from acid pregnant leach solutions obtained from Polish uranium ores: dictyonema shales and sandstone rocks. Ion exchange chromatography was applied for uranium sorption, using commercially available, strongly basic anion exchanger, Dowex 1 . In model experiments, the influence of degree of crosslinking of Dowex 1 on the efficiency of uranium extraction was investigated. The effect of $\mathrm{H}_{2} \mathrm{SO}_{4}$ concentration on the breakthrough curve of uranyl ions for the Dowex 1 resins, of different crosslinking: X4, X8 and X10, was examined. Unexpectedly high increase of exchange capacity of uranium was observed in case of Dowex 1X10. This gives potential opportunity of improving the effectiveness of uranium recovery process. Applying column packed with Dowex 1X10, 'yellow cake' with ca. 92\% yield and high purity of recovered uranium was obtained. A block diagram of the procedure for uranium and lanthanides extraction from acidic leach liquor has been proposed.
\end{abstract}

Keywords: uranium recovery $\bullet$ acidic pregnant leach solution $\bullet$ ion exchange separation

B. Danko, R. S. Dybczyński, Z. Samczyński ${ }^{\bowtie}$, E. Chajduk, K. Kulisa

Laboratory of Nuclear Analytical Techniques, Institute of Nuclear Chemistry and Technology, 16 Dorodna Str., 03-195 Warsaw, Poland, E-mail: z.samczyński@ichtj.waw.pl

D. Gajda, I. Herdzik-Koniecko,

G. Zakrzewska-Kołtuniewicz

Centre for Radiochemistry and Nuclear Chemistry, Institute of Nuclear Chemistry and Technology, 16 Dorodna Str., 03-195 Warsaw, Poland

Received: 26 October 2016

Accepted: 1 February 2017

\section{Introduction}

In the face of depletion of fossil resources, the development of nuclear power in the world is inevitable. Poland is one of the few developed countries, which does not have a nuclear power plant [1]. Therefore, The programme of Polish nuclear energy has recently been implemented. Simultaneously, the interest in domestic uranium ores, which first appeared in the fiftieth of the previous century, has been renewed.

Uranium is still recognized as a leading fission material. It is most often considered as the irreplaceable raw material for nuclear industry [2] and demand for uranium is expected to continue to rise in the foreseeable future. Therefore, studies on the prospects of uranium recovery from secondary sources are currently in progress. Although mining of domestic uranium deposits does not seem profitable, the situation could change along with changes in global uranium market [3]. Challenges for the future include the recovery of uranium from resources that may be of lower grade and located deeper than recently processed deposits. According to the current state of knowledge and assessment carried out by 
the Polish Geological Institute-National Research Institute $[4,5]$ the only uranium ores found in Poland are of low-grade. The most promising uranium mineralization occurs in the Lower and Middle Triassic sandstone rocks of the central part of Peribaltic Syneclise, where the maximum U content is $1.5 \%$. The other deposits of uranium are found in the Ordovician Dictyonema shales of Podlasie Depression (North-East Poland) with uranium concentration of 75-250 ppm. As it has been shown lately [6], the content of uranium in the above mentioned potential raw materials for the Polish nuclear industry, has a significant dispersion: $15-1480 \mathrm{ppm}$ and 3.3-1316 ppm, with mean values: $94.1 \mathrm{ppm}$ and $256 \mathrm{ppm}$, for dictyonema shales and sandstones, respectively.

The leaching studies conducted at the Institute of Nuclear Chemistry and Technology (INCT) to develop a suitable method for extraction of uranium from domestic ores were described in detail in recent articles [7-9].

In the current work, acidic leaching was used for uranium extraction, as it has the advantages of being more effective - requiring lower temperatures and leaching times. Moreover, the particle size from the grinding process does not need to be very small, as it is required in case of alkaline leaching [10]. Sulphuric acid used as leaching agent, typically combines high leach performance and relatively low cost [11].

For the recovery of uranium from pregnant leach solutions, ion exchange separation was applied. The sorption of uranium from sulphuric acid solutions by strongly basic anion exchange resin is widely described in literature [12-19]. Strongly basic anionic exchangers were often utilized in uranium industry [20-22] and are even recognized as the most suitable ion exchangers for uranium recovery [23]. Dowex 1, DVB gel type strongly basic anion exchanger, which is commercially available, was chosen for the current study. As can be inferred from the published data, in low sulphuric acid concentration, this resin seems to fulfil the requirement of good selectivity for uranium as compared to the elements potentially present in the leach liquor, such as $\mathrm{Co}, \mathrm{Cr}, \mathrm{Cu}, \mathrm{Fe}, \mathrm{La}, \mathrm{Mn}, \mathrm{Mo}$, $\mathrm{Ni}, \mathrm{Sb}, \mathrm{Th}, \mathrm{V}, \mathrm{Yb}$ and $\mathrm{Zn}$.

The usefulness of Dowex 1 for uranium recovery is confirmed in numerous papers. However, the authors do not provide information about the degree of crosslinking of the ion exchanger used. Cross-linkage is an essential parameter which may profoundly affect the ion-exchange behaviour especially in the case of large complex anions $[16,24,25]$. In these works, the influence of degree of crosslinking of Dowex 1 on the efficiency of uranium extraction was investigated.

Breakthrough studies in model experiments were conducted with pure uranium solution for the resin of various degree of crosslinking: $\mathrm{X} 4, \mathrm{X} 8$ and $\mathrm{X} 10$, to obtain the necessary information about the ion exchange process aimed at selective separation of uranium from accompanying elements. On the basis of model experiments, the investigations with real leaching solution were carried out.

The ultimate goal of this work is to propose the procedure for uranium and lanthanides extraction from acidic leach liquor, which can be potentially used in the development of Polish nuclear energy. Because Polish uranium ores are low-grade, the combination of uranium production and the recovery of rare earth metals can provide economic justification for the processing of these ores.

\section{Experimental section}

\section{Materials}

Pregnant leach solutions (PLS) of dictyonema shales and sandstone rocks.

Acidic pregnant leach solution of dictyonemic shales was obtained after leaching the uranium ore in an autoclave [8]. Autoclave leaching of the uranium ores was performed with the use of $10 \% \mathrm{H}_{2} \mathrm{SO}_{4}$, at temperature range of $80-160^{\circ} \mathrm{C}$, under pressure of 3-7 bar and for 1-2 hours, to determine the optimum conditions for leaching.

Large volume sample, PLS-1 $(1000 \mathrm{~mL})$ was prepared by combination of 20 independent acidic pregnant liquors, $50 \mathrm{~mL}$ each, from separate experiments [7]. Various samples of sandstone rocks were leached with $10 \% \mathrm{H}_{2} \mathrm{SO}_{4}$ as a lixiviant in the presence of one of the oxidation agents $\left(\mathrm{MnO}_{2}\right.$, $\mathrm{KMnO}_{4}, 30 \% \mathrm{H}_{2} \mathrm{O}_{2}, \mathrm{KClO}_{3}$ ) to convert the tetravalent uranium to the hexavalent state. The samples of sandstones were leached within one hour at temperature of $60^{\circ} \mathrm{C}$. Pregnant solution was diluted with distilled water to the volume of $50 \mathrm{~mL}$ [26]. Large volume sample of PLS-2 $(1000 \mathrm{~mL})$ from leaching the sandstones, was prepared by a combination of 20 independent acidic pregnant liquors.

PLS-3 - third acidic pregnant solution, dedicated to a larger scale experiments, was prepared by collecting 140 acidic pregnant solution samples of $50 \mathrm{~mL}$, after sandstones leaching.

\section{lon exchange resins}

Strongly basic ion exchange resins: Dowex $1 \mathrm{X} 4$ $\left[\mathrm{Cl}^{-}\right]$, Dowex $1 \mathrm{X} 8\left[\mathrm{Cl}^{-}\right]$, and Dowex $1 \mathrm{X} 10\left[\mathrm{Cl}^{-}\right]$ 200-400 mesh (Fluka AG) were used. The resins were conditioned by passing through the column: $1 \mathrm{~mol} \cdot \mathrm{L}^{-1} \mathrm{NaOH}$, distilled water and $1 \mathrm{~mol} \cdot \mathrm{L}^{-1} \mathrm{HCl}$, sequentially. Before carrying out the experiments, the resins were converted into the $\left[\mathrm{SO}_{4}^{2-}, \mathrm{HSO}_{4}^{-}\right]$ forms by washing with $1 \mathrm{~mol} \cdot \mathrm{L}^{-1} \mathrm{H}_{2} \mathrm{SO}_{4}$ followed by washing with water and dilute $\mathrm{H}_{2} \mathrm{SO}_{4}$ of appropriate concentration. All reagents were of analytical grade. High-purity water was obtained from the ultra-pure water system, Millipore.

\section{Instrumentation}

Philips PU 8625 UV/VIS spectrophotometer was employed for the measurement of absorbance of uranium complexes with Arsenazo III.

Dionex 2000i/SP ion chromatograph [27] was equipped with analytical anion exchange column Ion 
Table 1. The experimental conditions for ICP-MS measurements

\begin{tabular}{lc}
\hline RF power & $1000 \mathrm{~W}$ \\
Nebulizer gas flow rate & $0.95 \mathrm{~L} \cdot \mathrm{min}^{-1}$ \\
Plasma gas flow rate & $15 \mathrm{~L} \cdot \mathrm{min}^{-1}$ \\
Auxiliary gas flow rate & $1.2 \mathrm{~L} \cdot \mathrm{min}^{-1}$ \\
Lens voltage & $6.75 \mathrm{~V}$ \\
Detector mode & dual \\
Measurement unit & $\mathrm{cps}$ \\
Working mode & standard \\
\hline
\end{tabular}

Pac AS9HC, connected with guard column AG9HC, conductivity detector CDM II and the suppression system ASRS $4 \mathrm{~mm}$. The eluent used was $9 \mathrm{mmol} \cdot \mathrm{L}^{-1}$ $\mathrm{Na}_{2} \mathrm{CO}_{3}$.

The ELAN DRC II inductively coupled plasma quadrupole mass spectrometer (PerkinElmer) with crossflow nebulizer with Scott double-pass spray chamber and Ni cones was used in the work for multi elemental analysis. Instrument operation conditions are summarized in Table 1.

\section{Methods}

\section{Determination of breakthrough curves}

\section{Uranium in model experiments}

Dilute $\mathrm{H}_{2} \mathrm{SO}_{4}$ solution of established concentration, containing trace amounts of uranium was continuously passed through the column: $0.071 \mathrm{~cm}^{2} \times$ $5.0 \mathrm{~cm}$, filled with a given anion exchange resin (Dowex 1X4 or Dowex 1X8 or Dowex 1X10). The effluent was collected in fractions of 5-100 drops in test tubes. The obtained fractions were then analysed for uranium concentration. The breakthrough curve was obtained by plotting $C / C_{0}$ vs. $U$, where $C$ is the concentration of uranium in the effluent, $C_{0}$ is its concentration in the influent, and $U$ is the effluent volume. The mass distribution coefficient $\lambda$ was calculated from the equation [16]:

$$
\lambda=\frac{U-U_{0}-V}{m_{r}}
$$

where $U_{0}$ denotes dead volume of the column [mL], $U$ - effluent volume at $C=C_{0} / 2, V$ - free volume of the resin bed $[\mathrm{mL}], m_{r}-$ mass of the dry ion exchanger $[\mathrm{g}]$.

\section{Uranium and other examined ions in pregnant leach solution}

Column preparation: a glass column $\left(0.071 \mathrm{~cm}^{2} \times\right.$ $5.0 \mathrm{~cm}$ ) was packed with Dowex 1X8 or Dowex $1 \mathrm{X} 10$ resin. Prior to the experiments, the wet resin bed in the column was conditioned with excess of $0.15 \mathrm{~mol} \cdot \mathrm{L}^{-1}$ of sulphuric acid solution after pretreating with $2 \mathrm{~mol} \cdot \mathrm{L}^{-1} \mathrm{H}_{2} \mathrm{SO}_{4}$ (to convert the resin into the $\left[\mathrm{SO}_{4}^{2-}, \mathrm{HSO}_{4}^{-}\right]$forms) and rinsing with distilled water.

The pregnant leach solution of dictyonemic shales, PSL-1 (the mixture of uranium and other metals in $0.3 \mathrm{~mol} \cdot \mathrm{L}^{-1} \mathrm{H}_{2} \mathrm{SO}_{4}$ ) has been filtered off on ceramic filter G5 and after dilution with water (1:1) was continuously passed through the column filled with a given anion exchange resin: Dowex 1X8 or Dowex 1X10. The solution was fed into the column at a constant flow rate of $0.15 \mathrm{~mL} \cdot \mathrm{min}^{-1}$, controlled by the peristaltic pump. The effluent was collected in 1.5 or $3 \mathrm{~mL}$ portions.

The pregnant leach solutions of sandstones PLS-2 and PLS-3 (the mixture of uranium and other metals in $0.1 \mathrm{~mol} \cdot \mathrm{L}^{-1} \mathrm{H}_{2} \mathrm{SO}_{4}$ ) after filtration was directly passed through the column filled with anion exchange resin: Dowex 1X10.

\section{Analysis of the composition of the effluent solution}

\section{Model experiments}

The method of uranium determination by UV/VIS spectrophotometry is based on the complex formation of U (VI) with Arsenazo III (1,8-dihydroxynaphtalene-3,6-disulphonic acid-bis azophenyl arsenic acid) in solutions of $\mathrm{pH}$ close to 2 . The complex exhibits maximum absorption at the wavelength of $655 \mathrm{~nm}$ [28]. The fractions of the effluent collected in test tubes were diluted with appropriate and equal volume of water to attain $\mathrm{pH}$ of approx. 2. Then $50 \mu \mathrm{L}$ of $0.01 \%$ Arsenazo III solution was added and the solution was mixed. After 5 minutes, the absorbance of fractions were measured followed by calculation of uranium concentration on the basis of the calibration curve.

\section{Pregnant leach solutions}

Analysis of composition of the pregnant leach solutions used in this work, as well as the determination of the concentrations of elements of interest in each fraction was performed by inductively coupled plasma mass spectrometry (ICP-MS).

The following nuclides: ${ }^{238} \mathrm{U}$ and ${ }^{59} \mathrm{Co},{ }^{63} \mathrm{Cu},{ }^{52} \mathrm{Cr}$, ${ }^{139} \mathrm{La},{ }^{57} \mathrm{Fe},{ }^{55} \mathrm{Mn},{ }^{98} \mathrm{Mo},{ }^{60} \mathrm{Ni},{ }^{121} \mathrm{Sb},{ }^{232} \mathrm{Th},{ }^{51} \mathrm{~V},{ }^{66} \mathrm{Zn}$ and ${ }^{174} \mathrm{Yb}$ were selected for quantitative measurements since they were free from interference and were sufficiently abundant. Obtained solutions were diluted with $0.7 \% \mathrm{HNO}_{3}$ and indium was added as an internal standard prior to analysis. In-115 was chosen as an internal standard, due to its absence in the analysed samples, as well as owing to its mass number 115, which is between the lightest (51) and the heaviest (238) of the determined elements.

For the applied procedure in case of pregnant leach solution ICP-MS measurements, the expanded uncertainty $U(k=2)$ ranged from 5 to $15 \%$ in dependence on the element.

As the characteristics of the pregnant solutions varied significantly from experiment to experiment, the investigations were carried out using a uniform test-sample (PLS-1 or PLS-2, $1000 \mathrm{~mL}$ of volume) prepared by the compilation of individual portions, of post-leaching solution.

Determination of sulphates in the samples of solutions was performed with the use of the Dionex ion chromatograph. 
Table 2. The elemental characteristics of pregnant leach solutions

\begin{tabular}{lccc}
\hline & $\begin{array}{c}\mathrm{H}_{2} \mathrm{SO}_{4} \\
\text { concentration } \\
{\left[\mathrm{mol} \cdot \mathrm{L}^{-1}\right]}\end{array}$ & PLS-1 & PLS-2 \\
& 0.3 & 0.1 & PLS-3 \\
\hline $\mathrm{U}$ & $1.68 \pm 0.08$ & Content, $\mathrm{X} \pm \mathrm{U}\left[\mathrm{mg} \cdot \mathrm{L}^{-1}\right]$ & \\
$\mathrm{Co}$ & $0.43 \pm 0.04$ & $14.12 \pm 0.71$ & $7.45 \pm 0.37$ \\
$\mathrm{Cr}$ & $1.68 \pm 0.17$ & $0.09 \pm 0.01$ & $0.151 \pm 0.015$ \\
$\mathrm{Cu}$ & $2.41 \pm 0.24$ & $0.97 \pm 0.09$ & $0.105 \pm 0.011$ \\
$\mathrm{Fe}$ & $477.2 \pm 71.6$ & $0.41 \pm 0.04$ & $0.064 \pm 0.006$ \\
$\mathrm{La}$ & $0.20 \pm 0.02$ & $41.5 \pm 6.2$ & $24.2 \pm 3.7$ \\
$\mathrm{Mn}$ & $25.19 \pm 2.52$ & $0.11 \pm 0.01$ & $0.098 \pm 0.010$ \\
$\mathrm{Mo}$ & $4.00 \pm 0.4$ & $14.03 \pm 1.40$ & $13.69 \pm 1.4$ \\
$\mathrm{Ni}$ & $4.82 \pm 0.48$ & $\mathrm{nd}$ & $0.009 \pm 0.001$ \\
$\mathrm{Sb}$ & $0.011 \pm 0.001$ & $0.56 \pm 0.06$ & $0.061 \pm 0.006$ \\
$\mathrm{Th}$ & $0.20 \pm 0.01$ & nd & $0.003 \pm 0.001$ \\
$\mathrm{~V}$ & $17.78 \pm 1.78$ & $0.03 \pm 0.002$ & $0.025 \pm 0.001$ \\
$\mathrm{Yb}$ & $0.021 \pm 0.003$ & $1.82 \pm 0.18$ & $1.29 \pm 0.13$ \\
$\mathrm{Zn}$ & $92.01 \pm 9.20$ & $0.01 \pm 0.002$ & $0.011 \pm 0.002$ \\
\hline$U-$ expanded uncertainty $(k=2)$. & nd - below detection limit. & $1.24 \pm 0.12$
\end{tabular}

\section{Extraction of uranium from PLS-3. Large scale experiment}

$935 \mathrm{~mL}$ of PSL-3 was passed through Dowex $1 \mathrm{X} 10$ column $\left(0.44 \mathrm{~cm}^{2} \times 5 \mathrm{~cm}\right)$, previously conditioned with $1 \mathrm{~mol} \cdot \mathrm{L}^{-1} \mathrm{H}_{2} \mathrm{SO}_{4}$ and rinsed with water. Subsequently, $50 \mathrm{~mL}$ of $0.1 \mathrm{~mol} \cdot \mathrm{L}^{-1} \mathrm{H}_{2} \mathrm{SO}_{4}$ solution passed through the column. Then $50 \mathrm{~mL}$ of $1 \mathrm{~mol} \cdot \mathrm{L}^{-1}$ $\mathrm{H}_{2} \mathrm{SO}_{4}$ solution was introduced onto the column and uranium was quantitatively eluted. The purity of uranium extracted from pregnant leach solution was checked by ICP-MS analysis.

The elemental composition of a uniform, large volume samples of pregnant leach solution PLS-1, PLS-2 and PLS-3 is presented in Table 2. The concentration of sulphuric acid was estimated by ion chromatography (IC).

\section{'Yellow cake' precipitation}

The precipitation was carried out at temperature of ca. $60^{\circ} \mathrm{C}$. Ammonia solution $(32 \%)$ was gradually added, while stirring, until pH 10 was obtained. After 30 minutes, the reaction mixture was allowed to cool, switching off the stirrer. Yellow precipitate of ammonium diuranate $\left(\mathrm{NH}_{4}\right)_{2} \mathrm{U}_{2} \mathrm{O}_{7}$, generated during the production of 'yellow cake' was observed 40 minutes later. After centrifugation (6000 rpm) the solution was decanted, then analysed.

\section{Results and discussion}

\section{Uranium speciation}

Uranium forms the following stable complexes with sulphate ions: $\mathrm{UO}_{2} \mathrm{SO}_{4}, \mathrm{UO}_{2}\left(\mathrm{SO}_{4}\right)_{2}^{2-}$ and
$\mathrm{UO}_{2}\left(\mathrm{SO}_{4}\right)_{3}^{4-}$. The values of their cumulative stability constants $(\beta)$ are $64.6,316$ and 5012, respectively [29]. The mole fraction $(\Phi)$ of individual species can be calculated from the known equation [30]:

$$
\Phi_{i}=\frac{\beta_{i}[\mathrm{~L}]^{i}}{1+\sum_{i=1}^{N} \beta_{i}[\mathrm{~L}]^{i}}
$$

where $\mathrm{L}$ denotes ligand (in this case $\mathrm{SO}_{4}^{2-}$ ion).

Mole fractions of $\mathrm{UO}_{2}^{2+}-\mathrm{SO}_{4}^{2-}$ complexes as a function of the ligand concentration are shown in Fig. 1.

\section{Ion exchange reaction}

As can be seen, at concentration of $\mathrm{SO}_{4}^{2-}$ exceeding $0.1 \mathrm{~mol} \cdot \mathrm{L}^{-1}$ uranium exists predominantly in the form of the anion $\mathrm{UO}_{2}\left(\mathrm{SO}_{4}\right)_{3}^{4-}$. Its sorption by strongly basic ion exchange resins of Dowex 1 type can be schematically written as:

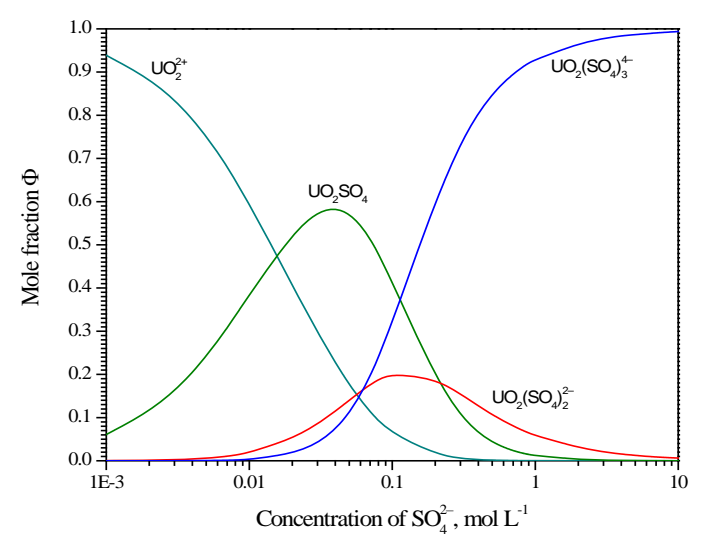

Fig. 1. Mole fractions of uranium sulphate complexes as a function of $\mathrm{SO}_{4}^{2-}$ concentration. 
(3) $\mathrm{UO}_{2}\left(\mathrm{SO}_{4}\right)_{3}^{4-}+2 \overline{\mathrm{R}_{2} \mathrm{SO}_{4}} \rightarrow \overline{\mathrm{R}_{4} \mathrm{UO}_{2}\left(\mathrm{SO}_{4}\right)_{3}}+2 \mathrm{SO}_{4}^{2-}$

where barred symbols refer to the ion exchanger phase and $\mathrm{R}$ denotes a structural unit of an ion exchanger. The selectivity coefficient is given by:

$$
\begin{aligned}
k_{\mathrm{HSO}_{4}^{-}}^{\mathrm{UO}_{2}\left(\mathrm{SO}_{4}\right)^{4-}} & =\frac{\left[\overline{\mathrm{R}_{4} \mathrm{UO}_{2}\left(\mathrm{SO}_{4}\right)_{3}}\right]\left[\mathrm{HSO}_{4}^{-}\right]^{4}}{\left[\mathrm{UO}_{2}\left(\mathrm{SO}_{4}\right)_{3}^{4-}\right]\left[\overline{\mathrm{RHSO}_{4}}\right]^{4}} \\
& =\lambda_{\mathrm{UO}_{2}\left(\mathrm{SO}_{4}\right)_{3}^{4-}} \frac{\left[\mathrm{HSO}_{4}^{-}\right]^{4}}{\left[\overline{\mathrm{RHSO}_{4}}\right]^{4}}
\end{aligned}
$$

where $\lambda$ is the mass distribution coefficient. After rearrangement and transformation into logarithmic form, the following expression is obtained:

$$
\begin{aligned}
\log \lambda_{\mathrm{UO}_{2}\left(\mathrm{SO}_{4}\right)_{3}^{4^{-}}}= & \log k_{\mathrm{SO}_{4}^{2-}}^{\mathrm{UO}_{2}\left(\mathrm{SO}_{4}\right)_{3}^{4^{-}}}+2 \log \left[\overline{\mathrm{R}_{2} \mathrm{SO}_{4}}\right] \\
& -2 \log \left[\mathrm{SO}_{4}^{2-}\right]
\end{aligned}
$$

Differentiation with respect to $\left[\mathrm{SO}_{4}^{2-}\right]$ leads to the equation:

$$
\frac{d \log \lambda_{\mathrm{UO}_{2}\left(\mathrm{SO}_{4}\right)_{3}^{-}}}{d \log \left[\mathrm{SO}_{4}^{2-}\right]}=-2
$$

As the strongly basic anion exchanger in contact with the $0.1 \mathrm{~mol} \cdot \mathrm{L}^{-1} \mathrm{H}_{2} \mathrm{SO}_{4}$ is in the mixed: $\left[\mathrm{HSO}_{4}^{-}\right.$; $\mathrm{SO}_{4}^{2-}$ ] form [31], one should also take into account the alternative reaction:

$$
\begin{aligned}
& \mathrm{UO}_{2}\left(\mathrm{SO}_{4}\right)_{3}^{4-}+4 \overline{\mathrm{RHSO}_{4}} \rightarrow \overline{\mathrm{R}_{4} \mathrm{UO}_{2}\left(\mathrm{SO}_{4}\right)_{3}} \\
&+4 \mathrm{HSO}_{4}^{-} \\
& k_{\mathrm{SO}_{4}^{2-}}^{\mathrm{UO}_{4}\left(\mathrm{SO}_{4}\right)_{5}^{4-}}=\frac{\left[\overline{\mathrm{R}_{4} \mathrm{UO}_{2}\left(\mathrm{SO}_{4}\right)_{3}}\right]\left[\mathrm{SO}_{4}^{2-}\right]^{2}}{\left[\mathrm{UO}_{2}\left(\mathrm{SO}_{4}\right)_{3}^{4-}\right]\left[\overline{\left.\mathrm{R}_{2} \mathrm{SO}_{4}\right]^{2}}\right.} \\
&= \lambda_{\mathrm{UO}_{2}\left(\mathrm{SO}_{4}\right)_{3}^{-\frac{4}{3}}} \frac{\left[\mathrm{SO}_{4}^{2-}\right]^{2}}{\left[\mathrm{R}_{2} \mathrm{SO}_{4}\right]^{2}} \\
& \frac{d \log \lambda_{\mathrm{UO}_{2}\left(\mathrm{SO}_{4}\right)_{3}^{-4}}}{d \log \left[\mathrm{HSO}_{4}^{-}\right]}=-4
\end{aligned}
$$

The equilibrium $\mathrm{HSO}_{4}^{-}-\mathrm{SO}_{4}^{2-}$ in the resin is given by the relation [31]:

$$
\frac{\bar{X}}{(1-\bar{X})^{2}}=k_{\mathrm{HSO}_{4}^{-}}^{\mathrm{SO}_{4}^{2-}} \frac{C_{r}}{C_{s}} \cdot \frac{X}{(1-X)^{2}}
$$

where: $X$ denotes equivalent fraction of sulphate, barred symbols refer to the resin phase, $C_{r}$ and $C_{s}$ are the total equivalent concentrations of anions in the resin phase and in solution, respectively. The results of slope analysis (cf. Fig. 2) seem to indicate the increasing share of reaction (7) with an increase in resin crosslinking. This result is in apparent contradiction with the theory, because as follows from Eq. (10), with an increase in crosslinking, the value $C_{r}$ should increase and by the same token the share of $\mathrm{HSO}_{4}^{-}$in the resin phase should decrease. The plausible explanation could be that because of lower swelling and smaller water content of the resin phase, the spatial requirements for accommodating strongly hydrated sulphate anion become more unfavourable and the equivalent fraction of $\mathrm{HSO}_{4}^{-}$in the resin phase of Dowex $1 \mathrm{X} 10$ from the beginning is considerably greater in comparison

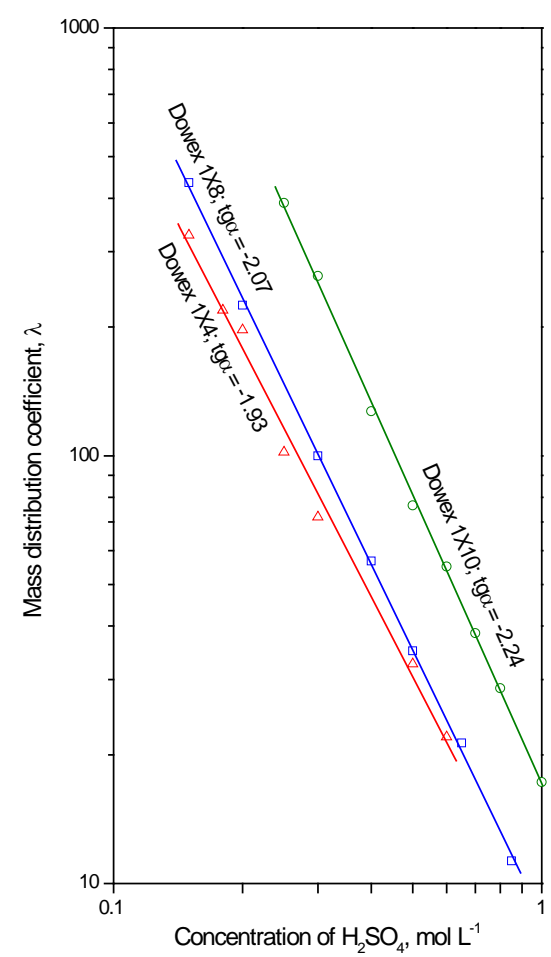

Fig. 2. Mass distribution coefficient of uranium as a function of $\mathrm{H}_{2} \mathrm{SO}_{4}$ concentration for anion exchange resins of Dowex 1 type varying in degree of crosslinking: $\mathrm{X} 4$, $\mathrm{X} 8$ and X10.

with the analogous situation in resins with lower crosslinking. The unexpectedly significant increase of selectivity of Dowex 1X10 for uranium in the system studied in comparison with resins of lower crosslinking is an experimental fact and can be used with advantage for uranium separation. Numerous elements, such as alkaline metals, alkaline earth metals, Al, As(III), Au, Be, Cd, Co, Cu, Fe(II), La and the lanthanides, Mg, Mn(II), Ni, Sb(III), Zn, Y, $\mathrm{V}(\mathrm{IV})$, are not practically absorbed in the solution of $0.05-5 \mathrm{~mol} \cdot \mathrm{L}^{-1} \mathrm{H}_{2} \mathrm{SO}_{4}$.

\section{Breakthrough curves}

The effect of $\mathrm{H}_{2} \mathrm{SO}_{4}$ concentration on the breakthrough curves of uranyl ions for the resins Dowex 1 of different crosslinking was examined (Fig. 3). It is assumed in this work that the breakthrough point occurs when $C / C_{0}$ attains value 0.01 . On the basis of the model experiments with uranium, the conditions for pregnant leach solution investigation were chosen: Dowex 1 of crosslinking $\geq \mathrm{X} 8$ in $0.15 \mathrm{~mol} \cdot \mathrm{L}^{-1} \mathrm{H}_{2} \mathrm{SO}_{4}$.

The breakthrough curves for uranium and other elements in leach solution PLS-1 obtained employing anion exchangers of crosslinking X8 and X10 are shown in Fig. 4.

Surprisingly, it turned out based on the model experiments (Fig. 3) and it was confirmed in pregnant leach solution investigation as well (Fig. 4) that the most advantageous from the technological point of view was the resin with degree of crosslinking X10, where significantly higher sorption of uranium was noted (Fig. 5). 

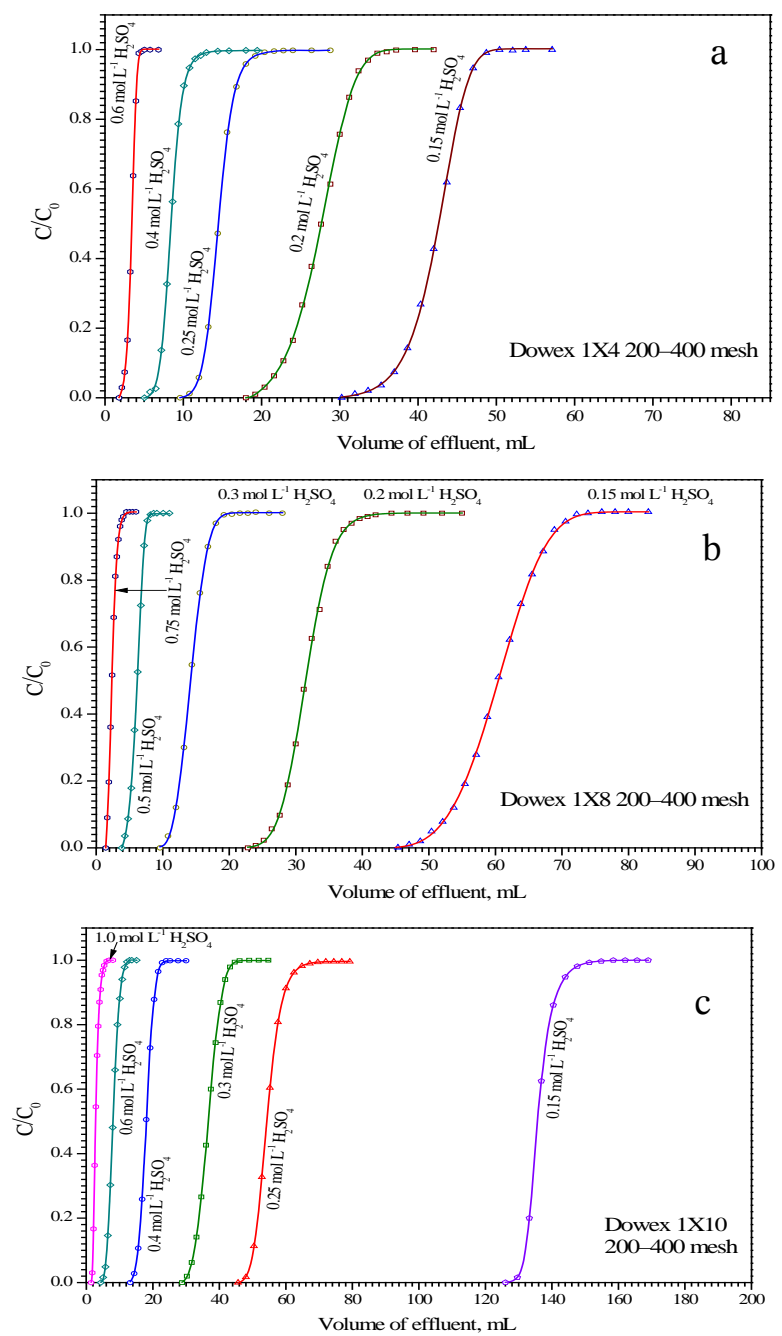

Fig. 3. The effect of $\mathrm{H}_{2} \mathrm{SO}_{4}$ concentration on the breakthrough curve of uranyl ions for resins of different crosslinking: X4 (a), X8 (b) and X10 (c). Concentration of the feed solution: $20 \mu \mathrm{g} \cdot \mathrm{mL}^{-1} \mathrm{UO}_{2}{ }^{2-}$. Column: $0.071 \mathrm{~cm}^{2} \times$ $5.0 \mathrm{~cm} ; t=20^{\circ} \mathrm{C} ; u=0.75 \mathrm{~cm} \cdot \mathrm{min}^{-1}$.

The resin of choice, with preferred crosslinking (X10) shows not only good selectivity for uranium over other impurities in the leach liquor, but it also has three times higher exchange capacity for uranium with respect to the resin of lower crosslinking. As it was recognized, about $20 \mathrm{mg}$ of uranium per $\mathrm{kg}$ of dry resin could be absorbed in Dowex 1X10 from $0.1 \mathrm{~mol} \cdot \mathrm{L}^{-1}$ sulphuric acid, while in the case of Dowex 1X8 and Dowex 1X4, this quantity did not exceed 7 and 5 , respectively.

The breakthrough curve for uranium retained on Dowex 1X10 from the solution PLS-2 of higher uranium content $\left(14.12 \mathrm{mg} \cdot \mathrm{L}^{-1}\right)$ and lower $\mathrm{H}_{2} \mathrm{SO}_{4}$ concentration in the feed solution $\left(0.08 \mathrm{~mol} \cdot \mathrm{L}^{-1}\right)$ is shown in Fig. 6.

The results of the experiments mentioned above served as a reference for designing the process of extracting uranium from pregnant leach solution, followed by 'yellow cake' precipitation. Therefore, the larger scale experiments were carried out, using PLS-3 as feed solution. After passing a large volume of PSL-3 (much below the breakthrough volume of the column with regard to uranium), the residues of other metals, present in the interstitial
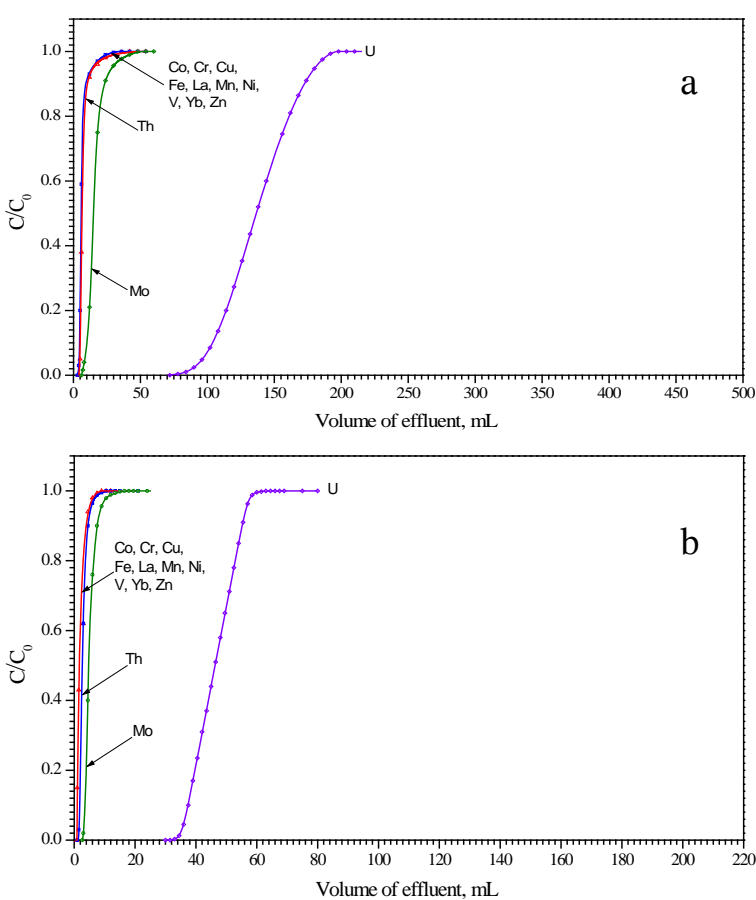

Fig. 4. Breakthrough curves for the uranyl sulphate complex anion adsorption in anion exchange resins: (a) Dowex 1X8 200-400 mesh and (b) Dowex 1X10, 200-400 mesh at room temperature. $C$ - concentration of uranium in effluent; $C_{0}$ - concentration of uranium in original feed solution PLS-1 (dictyonemic shales in $\left.0.15 \mathrm{~mol} \cdot \mathrm{L}^{-1} \mathrm{H}_{2} \mathrm{SO}_{4}\right)$. Column: $0.071 \mathrm{~cm}^{2} \times 5.0 \mathrm{~cm}$.

volume of the bed of ion exchanger, were carefully washed out with $0.1 \mathrm{~mol} \cdot \mathrm{L}^{-1} \mathrm{H}_{2} \mathrm{SO}_{4}$. Then uranium

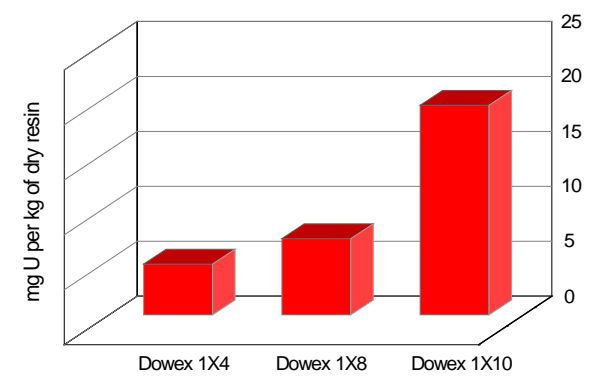

Fig. 5. Sorption of uranium by Dowex 1 (200-400 mesh) of various crosslinking (model experiments). Column: $0.071 \mathrm{~cm}^{2} \times 5.0 \mathrm{~cm}$.

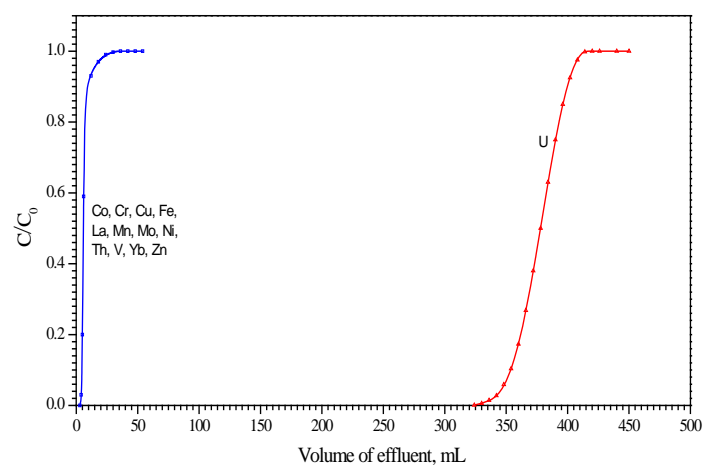

Fig. 6. Breakthrough curves for uranium and accompanying metals obtained using anion exchange resin Dowex $1 \mathrm{X} 10,200-400$ mesh at room temperature. $C_{0}$ - concentration of $U$ in the original feed solution: PLS-2 (sandstone rock in $\left.0.08 \mathrm{~mol} \cdot \mathrm{L}^{-1} \mathrm{H}_{2} \mathrm{SO}_{4}\right) ; C$ - concentration of $\mathrm{U}$ in the effluent. Column: $0.071 \mathrm{~cm}^{2} \times 5.0 \mathrm{~cm}$. 


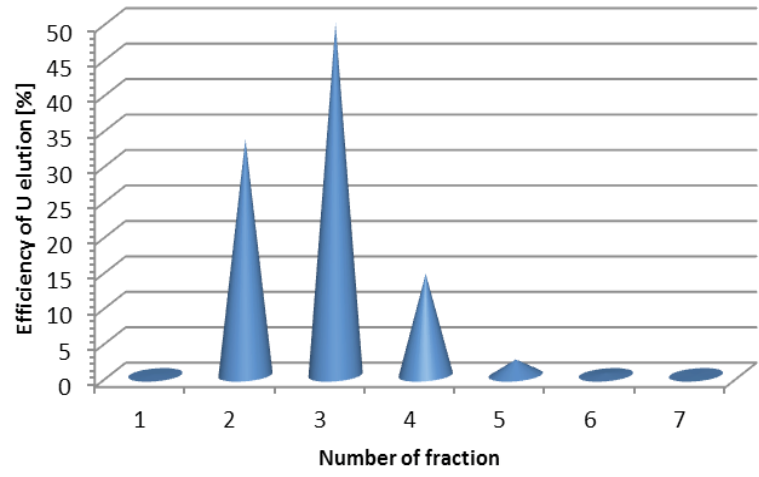

Fig. 7. Efficiency of uranium elution from Dowex $1 \mathrm{X} 10$ using $1 \mathrm{~mol} \cdot \mathrm{L}^{-1} \mathrm{H}_{2} \mathrm{SO}_{4}$. Column: $0.44 \mathrm{~cm}^{2} \times 5 \mathrm{~cm}$; volume of fraction $5 \mathrm{~mL}$.

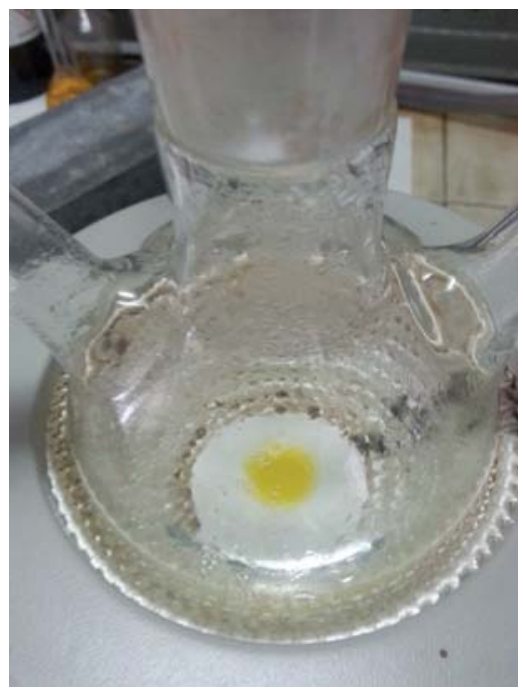

Fig. 8. 'Yellow cake' precipitated from acidic pregnant leach solution PLS-3.

was quantitatively and rapidly eluted with $1 \mathrm{~mol} \cdot \mathrm{L}^{-1}$ $\mathrm{H}_{2} \mathrm{SO}_{4}$, as it is shown in Fig. 7. The high purity of uranium - only small amounts of Ag, Mo and Th was observed - confirms the effectiveness of the applied process of ion exchange on Dowex 1X10 (Table 3).

\section{Recovery of uranium and lanthanides}

Subsequently 'yellow cake', which is formed according to the reaction:

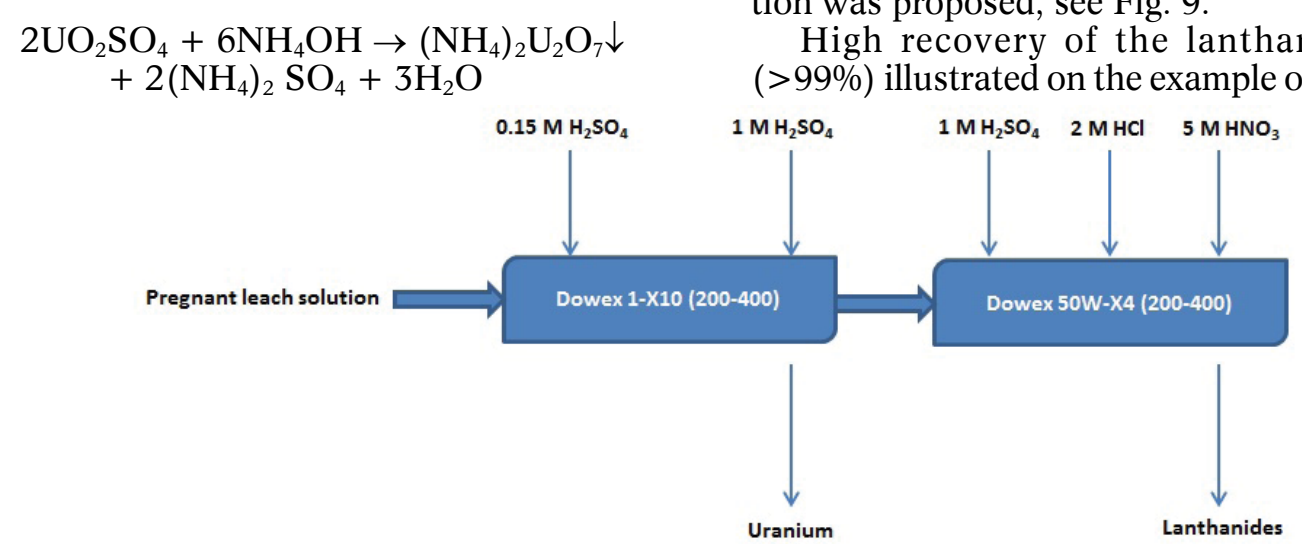

Fig. 9. Flowchart for uranium and the lanthanides recovery from the pregnant leach solution.
Table 3. Purity of uranium after the ion exchange process

\begin{tabular}{|c|c|c|c|}
\hline Element & $\begin{array}{l}\text { Mass of the } \\
\text { element } \\
\text { introduced onto } \\
\text { the column } \\
{[\mu \mathrm{g}]}\end{array}$ & $\begin{array}{l}\text { Mass found } \\
\text { in the U } \\
\text { fraction after } \\
\text { processing } \\
{[\mu \mathrm{g}]}\end{array}$ & $\begin{array}{c}\% \\
\text { of element }\end{array}$ \\
\hline$\overline{\mathrm{Ag}}$ & 0.711 & 0.045 & 6.3 \\
\hline $\mathrm{Al}$ & 37955 & nd & 0 \\
\hline As & 21.4 & nd & 0 \\
\hline $\mathrm{Ba}$ & 19.7 & nd & 0 \\
\hline $\mathrm{Be}$ & 5.59 & nd & 0 \\
\hline $\mathrm{Cd}$ & 3.32 & nd & 0 \\
\hline $\mathrm{Ce}$ & 167 & nd & 0 \\
\hline Co & 142 & nd & 0 \\
\hline $\mathrm{Cr}$ & 98.2 & nd & 0 \\
\hline $\mathrm{Cu}$ & 60.0 & nd & 0 \\
\hline $\mathrm{Fe}$ & 22639 & nd & 0 \\
\hline $\mathrm{La}$ & 91.8 & nd & 0 \\
\hline $\mathrm{Li}$ & 75.5 & nd & 0 \\
\hline $\mathrm{Lu}$ & 2.51 & nd & 0 \\
\hline $\mathrm{Mg}$ & 70361 & nd & 0 \\
\hline $\mathrm{Mn}$ & 12804 & nd & 0 \\
\hline Mo & 8.42 & 0.7 & 8.3 \\
\hline $\mathrm{Ni}$ & 56.7 & nd & 0 \\
\hline $\mathrm{Pb}$ & 237 & nd & 0 \\
\hline $\mathrm{Sb}$ & 2.49 & nd & 0 \\
\hline Sc & 31.8 & nd & 0 \\
\hline $\mathrm{Se}$ & 13.4 & nd & 0 \\
\hline $\mathrm{Sr}$ & 428 & nd & 0 \\
\hline Th & 23.4 & 1.1 & 4.7 \\
\hline $\mathrm{Ti}$ & 2.04 & nd & 0 \\
\hline $\mathrm{U}$ & 6969 & 6949 & 99.7 \\
\hline V & 1214 & 0.1 & 0.01 \\
\hline $\mathrm{Yb}$ & 10.7 & nd & 0 \\
\hline $\mathrm{Zn}$ & 1161 & nd & 0 \\
\hline
\end{tabular}

nd - not detected.

has been precipitated (Fig. 8) with ca. 92\% recovery of uranium using the procedure proposed on the basis of experiments described in the paper [32]. In this work, other valuable metals present in uranium ores were considered, especially the lanthanides, which are extremely important for the development of modern technology. Based on the literature [17] and our previous research [33] a double column ion exchange procedure for uranium, as well as the lanthanides recovery from the pregnant leach solution was proposed, see Fig. 9.

High recovery of the lanthanides fraction $>99 \%$ ) illustrated on the example of $\mathrm{La}, \mathrm{Ce}$ and $\mathrm{Nd}$ 


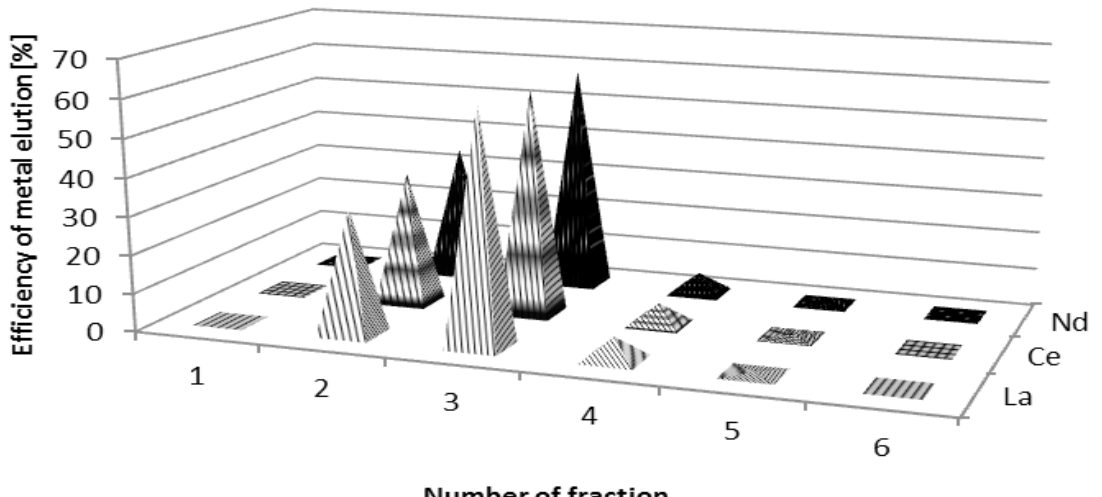

Fig. 10. Elution of some lanthanides from Dowex 50WX 4. 200-400 mesh with $5 \mathrm{~mol} \cdot \mathrm{L}^{-1} \mathrm{HNO}_{3}$. Column: $0.44 \mathrm{~cm}{ }^{2}$ $\times 8 \mathrm{~cm}$; volume of fraction $5 \mathrm{~mL}$.

Table 4. Impurities found in lanthanides fraction

\begin{tabular}{|c|c|c|c|}
\hline Element & $\begin{array}{l}\text { Mass of the } \\
\text { element } \\
\text { introduced onto } \\
\text { the column } \\
{[\mu \mathrm{g}]}\end{array}$ & $\begin{array}{l}\text { Mass found } \\
\text { in the } \\
\text { lanthanides } \\
\text { fraction after } \\
\text { processing }[\mu \mathrm{g}]\end{array}$ & $\begin{array}{c}\% \\
\text { of element }\end{array}$ \\
\hline$\overline{\mathrm{Ag}}$ & 1.35 & nd & 0 \\
\hline $\mathrm{Al}$ & 21453 & nd & 0 \\
\hline As & 10.8 & 0.561 & 5.2 \\
\hline $\mathrm{Ba}$ & 16.6 & 2.52 & 15.1 \\
\hline $\mathrm{Be}$ & 2.25 & 0.112 & 4.5 \\
\hline $\mathrm{Cd}$ & 1.98 & nd & 0 \\
\hline Co & 80.6 & 0.03 & 0.04 \\
\hline $\mathrm{Cr}$ & 72.1 & 0.532 & 0.7 \\
\hline $\mathrm{Cu}$ & 40.5 & nd & 0 \\
\hline $\mathrm{Fe}$ & 12717 & nd & 0 \\
\hline $\mathrm{Li}$ & 43.7 & nd & 0 \\
\hline $\mathrm{Mg}$ & 39230 & nd & 0 \\
\hline $\mathrm{Mn}$ & 7020 & 0.081 & 0.01 \\
\hline Mo & 1.81 & 0.168 & 9.3 \\
\hline $\mathrm{Ni}$ & 49.1 & nd & 0 \\
\hline $\mathrm{Pb}$ & 212 & nd & 0 \\
\hline $\mathrm{Sc}$ & 16.7 & 0.108 & 0.64 \\
\hline $\mathrm{Se}$ & 17.1 & nd & 0 \\
\hline $\mathrm{Sr}$ & 239 & nd & 0 \\
\hline Th & 5.42 & nd & 0 \\
\hline V & 691 & 0.56 & 0.08 \\
\hline Y & 4.51 & 4.79 & 106 \\
\hline $\mathrm{Zn}$ & 1161 & nd & 0 \\
\hline
\end{tabular}

nd - not detected.

(the most abundant lanthanides) (Fig. 10), as well as its purity (Table 4) is worth noting. Only slight traces of As, Sc, Ba, Be, Cr, Mn, Mo, Sc and V were detected. Yttrium accompanying light lanthanides indicates that also heavy lanthanides (if present) should be recovered with high yield in this process.

\section{Conclusions}

As it can be concluded from the studies of uranium sorption on Dowex 1 for different crosslinking, the most effective is Dowex 1X10. In this case, the ion exchange sorption capacity for uranium is three times higher, comparing to the most frequently used
Dowex 1X8. The conclusions derived from model experience have been confirmed in studies of real solutions obtained after leaching uranium ores. The use of Dowex 1X10 is highly beneficial for uranium extraction from acidic pregnant leach solutions.

Finally, the flowsheet for valuable metals extraction from pregnant leach liquor: uranium and the lanthanides, of recovery $93 \%$ and $99 \%$, respectively, has been proposed.

The proposed procedure seems to be promising, both on laboratory as well as on technical scale.

The paper demonstrates the usefulness of ion exchange process for the recovery of some precious metals from raw materials.

Acknowledgment. The studies were partly supported by the Operative Programme Innovative Economy, POIG entitled "Analysis of the possibility of uranium supply from domestic resources" (POIG 01.01.02-14094-09-00).

\section{References}

1. Chmielewski, A. G. (2013). Nuclear power for Poland. World J. Nucl. Sci. Technol., 3, 123-130. http:// dx.doi.org/10.4236/wjnst.2013.34021.

2. Ahmed, S. H., Sharaby, C. M., \& El Gammal, E. M. (2013). Uranium extraction from sulfuric acid medium using trioctylamine impregnated activated carbon. Hydrometallurgy, 134/135, 150-157.

3. Kahouli, S. (2011). Re-examining uranium supply and demand: New insights. Energy Policy, 39(1), 358-376.

4. Rejman, W. (1996). Uranium mines in Poland. Wiedza $i$ Życie, 9, 78-79 (in Polish).

5. Miecznik, J. B., Strzelecki, R., \& Wołkowicz, S. (2011). Uranium in Poland - history of prospecting and chances for finding new deposits. Prz. Geol., 59(10), 688-697 (in Polish).

6. Chajduk, E., Bartosiewicz, I., Pyszynska, M., Chwastowska, J., \& Polkowska-Motrenko, H. (2013). Determination of uranium and selected elements in Polish dictyonema shale and sandstones by ICP-MS. J. Radioanal. Nucl. Chem., 295, 1913-1919.

7. Frąckiewicz, K., Kiegiel, K., Herdzik-Koniecko, I., Chajduk, E., Zakrzewska-Trznadel, G., Wołkowicz, S., Chwastowska, J., \& Bartosiewicz, I. (2012). Extraction of uranium from low-grade Polish ores: 
dictyonemic shales and sandstones. Nukleonika, 58(4), 451-459.

8. Zakrzewska-Trznadel, G., Herdzik-Koniecko, I., Cojocaru, C., \& Chajduk, E. (2014). Experimental design and optimization of leaching process for recovery of valuable chemical elements $(\mathrm{U}, \mathrm{La}, \mathrm{V}, \mathrm{Mo}, \mathrm{Yb}$ and $\mathrm{Th}$ ) from low-grade uranium ore. J. Hazard. Mater., $275,136-145$.

9. Kiegiel, K., Zakrzewska-Kołtuniewicz, G., Gajda, D., Miśkiewicz, A., Abramowska, A., Biełuszko, P., Danko, B., Chajduk, E., \& Wołkowicz, S. (2015). Dictyonema black shale and Triassic sandstones as potential sources of uranium. Nukleonika, 60(3), 515-522. DOI: 10.1515/nuka-2015-0096.

10. Weil, B. (2012). Uranium mining and extraction from ore. Available from http://large.stanford.edu/ courses/2012/ph241/weil2/.

11. Bhargava, S. K., Ram, R., Pownceby, M., Grocott, S., Ring, B., Tardo, J., \& Jones, L. (2015). A review of acid leaching of uraninite. Hydrometallurgy, 151, 10-24.

12. Strelow, F. W. E., \& Bohma, C. J. C. (1967). Anion exchange and a selectivity scale for elements in sulfuric acid media with a strongly basic resin. Anal. Chem., 39(6), 595-599.

13. Kraus, K. A., \& Nelson, F. (1956). Anion-exchange studies of the fission products. In International Conference of the Peaceful Uses of Atomic Energy (Vol. 7, p. 113). Geneva, Switzerland: United Nations.

14. Greer, A. H., Mindler, A. B., \& Termini, J. P. (1958). New ion exchange resin for uranium recovery. Ind. Eng. Chem., 50(2), 166-170. DOI: 10.1021/ ie50578a028.

15. Marhol, M. (1982). Ion exchange in analytical chemistry. Prague: Academia.

16. Minczewski, J., Chwastowska, J., \& Dybczyński, R. (1982). Separation and preconcentration methods in inorganic trace analysis. Chichester: E. Horwood.

17. Ikeda, A., Aida, M., Fujii, Y., Kataoka, S., Annen, S., \& Sato, J. (2002). Ion exchange separation for decontamination of centrifuge enrichment plant. $J$. Nucl. Sci. Technol., 39(10), 1099-1105.

18. Kolomiets, D. N., Troshkina, L. D., Sheremet'ev, M. F., \& Konopleva, L. V. (2005). Sorption of uranium from sulfuric acid leaching solutions by strongly basic anion exchangers. Russ. J. Appl. Chem., 78(5), 722-726.

19. Zagorodnyaya, A. N., Abisheva, Z. S., Sharipova, A. S., Sadykanova, S. E., Bochevskaya, Y. G., \& Atanova, O. V. (2013). Sorption of rhenium and uranium by strong base anion exchange resin from solutions with different anion compositions. Hydrometallurgy, 131/132, 127-131.

20. Kunin, R., \& Preuss, A. F. (1956). Ion exchange in the atomic energy program. Ind. Eng. Chem., 48(8), 30A-35A.

21. Zontov, N. (2006). Continuous counter current ion exchange in uranium ore processing. In ALTA 2006 Uranium Conference.

22. Mikhaylenko, M., \& Van Deventer, J. (2009). Notes of practical application of ion exchange resins in uranium extractive. In ALTA 2009 Uranium Conference.

23. Carr, J., Zontov, N., \& Yamin, S. (2008). Meeting the future challenges of the uranium industry. In ALTA 2008 Uranium Conference, p. 20.

24. Dybczyński, R. (1970). Effect of resin crosslinking on the anion exchange separation of rare earth-EDTA complex. J. Chromatogr., 50, 487-503.

25. Dybczyński, R. (1972). Effect of resin crosslinking on the cation exchange separation of alkali and alkaline earth metals on sulfonic cation exchangers. J. Chromatogr., 71, 507-522.

26. Gajda, D., Kiegiel, K., Zakrzewska-Kołtuniewicz, G., Chajduk, E., Bartosiewicz, I., \& Wołkowicz, S. (2015). Mineralogy and uranium leaching of ores from Triassic Peribaltic Sandstones. I. Radioanal. Nucl. Chem., 303, 521-529.

27. Dionex Corporation. (1985). System 2000i/SP ion chromatograph operation and maintenance manual. Document No. 32584. Revision 01.

28. Marczenko, Z. (1976). Spectrophotometric determination of elements. London: Wiley.

29. Martell, R. M., \& Smith, A. E. (1976). Critical stability constants. New York: Plenum Press.

30. Inczedy, J. (1976). Analytical applications of complex equilibria. Chichester: E. Horwood.

31. Anderson, R. E., Bauman, W. C., \& Harrington, D. F. (1955). Sulfate-bisulfate equilibrium on anion exchange resins. Ind. Eng. Chem., 47, 1620-1623.

32. Kiegiel, K., Abramowska, A., Gajda, D., \& Zakrzewska, G. (2015). A study of precipitation of yellow cake for production of nuclear fuel. In INCT Annual Report 2014 (pp. 36-37). Warszawa: Institute of Nuclear Chemistry and Technology.

33. Danko, B., Samczyński, Z., \& Dybczyński, R. (2006). Analytical scheme for group separation of the lanthanides from biological materials before their determination by Neutron Activation Analysis. Chem. Anal., 51, 527-539. 